\title{
Spoken word frequency counts based on 1.6 million words in American English
}

\author{
Matthew J. Pastizzo and Robert F. Carbone, Jr. \\ State University of New York, Geneseo, New York
}

\begin{abstract}
Written word frequency (e.g., Francis \& Kučera, 1982; Kučera \& Francis, 1967) constitutes a popular measure of word familiarity, which is highly predictive of word recognition. Far less often, researchers employ spoken frequency counts in their studies. This discrepancy can be attributed most readily to the conspicuous absence of a sizeable spoken frequency count for American English. The present article reports the construction of a 1.6million-word spoken frequency database derived from the Michigan Corpus of Academic Spoken English (Simpson, Swales, \& Briggs, 2002). We generated spoken frequency counts for 34,922 words and extracted speaker attributes from the source material to generate relative frequencies of words spoken by each speaker category. We assess the predictive validity of these counts, and discuss some possible applications outside of word recognition studies.
\end{abstract}

The influence of word familiarity on word recognition has been very well established in the literature. Familiarity can be measured in a number of ways, typically in the form of written frequency, subjective ratings, or age of acquisition. In general, words that are more familiar are recognized more rapidly than those words that are less familiar (e.g., word frequency-Alegre \& Gordon, 1999; Connine \& Mullennix, 1990; age of acquisition-Dewhurst, Hitch, \& Barry, 1998; Gerhand \& Barry, 1998). When other factors such as word length are held constant, high frequency words or words acquired at an earlier age are recognized faster than low frequency words or words acquired at a later age. It should be noted that typically, the earliest words acquired are learned through conversation. Moreover, throughout a lifetime, most individuals (presumably) encounter words more often in speech than in texts, and this reality highlights the importance of suitable spoken counts to analyze speechbased word familiarity. Although written frequency counts are readily available (most notably, Francis \& Kučera, 1982; Kučera \& Francis, 1967), few (if any) spoken counts exist for American English. The present paper reports the construction of a 1.6 million word spoken frequency database tagged for speaker attributes such as gender and age.

The use of spoken word frequency counts is conspicuously absent in the literature, presumably due to a lack of appropriate frequency counts for American English. The most notable spoken frequency database is based on a British English corpus of 190,000 words (which included 10,630 different words) that were recorded without the direct knowledge of the speaker (Brown, 1984). Given the inherent difficulty of speech transcription for the purpose of generating spoken counts, the Brown (1984) corpus is commendable, although still considerably smaller in scope than typical written frequency databases (e.g., Kučera \& Francis, 1967, collected over 1 million words representative of over 40,000 different words). The discrepancy in scope between spoken and written counts in conjunction with the absence of a large-scale spoken frequency database in American English motivated the construction of a new spoken frequency database.

\section{Spoken English Corpus}

Our spoken frequency counts were derived from the Michigan Corpus of Academic Spoken English (MICASE). The corpus is available online, and includes 152 transcriptions of lectures, meetings, advisement sessions, public addresses, and other educational conversations recorded at the University of Michigan (Simpson, Swales, \& Briggs, 2002). On average, each of the 152 transcriptions contains approximately 11,000 words spoken by students, faculty, and other staff members in a variety of academic fields. The speakers ranged in age and gender and a majority of the speakers were educated native speakers of American English with a small percentage of nonnative speakers. In total, the transcripts derive from approximately 190 hours of recordings made between 1997 and 2001. Further information about how these recordings were collected as well as summaries of speaker attributes and speech contexts can be obtained from the MICASE Web site (Simpson et al., 2002).

Although the MICASE contains 1,848,364 spoken words (i.e., token count), 152,824 tokens were excluded because the speakers did not give their consent for their data to be used for research. After removing an additional 29,919 tokens that were read aloud from a written source ${ }^{1}$ by the speaker as well as 35,245 tokens that could not be transcribed accurately, we extracted 1,630,376 tokens from the 152 MICASE transcripts, which represented 34,922 different words (i.e., type count).

\section{Spoken Frequency Database}

To construct the spoken frequency database, we first downloaded all 152 transcriptions in an html format. We

M. J. Pastizzo, pastizzo@geneseo.edu 
Table 1

Numbers of Different Words (Type Count) and

Total Numbers of Words Spoken (Token Count) As a Function of Each Speaker Attribute

\begin{tabular}{|c|c|c|c|}
\hline \multirow{2}{*}{$\begin{array}{c}\text { Participant } \\
\text { Characteristics }\end{array}$} & \multicolumn{3}{|c|}{ Count } \\
\hline & Type & Token & $\%$ Total \\
\hline \multicolumn{4}{|l|}{ Language Status } \\
\hline Native & 32,463 & $1,404,006$ & 86 \\
\hline Near native & 7,806 & 121,206 & 7 \\
\hline Nonnative & 5,501 & 74,368 & 5 \\
\hline Non-American English & 3,250 & 30,796 & 2 \\
\hline Total & & $1,630,376$ & \\
\hline \multicolumn{4}{|l|}{ College Role } \\
\hline Faculty & 25,544 & 804,238 & 49 \\
\hline Graduate student & 13,500 & 358,233 & 22 \\
\hline Undergraduate & 13,904 & 350,251 & 21 \\
\hline Other & 5,928 & 83,719 & 5 \\
\hline Unknown & 3,801 & 33,935 & 2 \\
\hline Total & & $1,630,376$ & \\
\hline \multicolumn{4}{|l|}{ Gender } \\
\hline Female & 24,541 & 878,261 & 54 \\
\hline Male & 23,617 & 751,188 & 46 \\
\hline Unknown & 479 & 927 & $<1$ \\
\hline Total & & $1,630,376$ & \\
\hline \multicolumn{4}{|l|}{ Age (years) } \\
\hline $17-23$ & 15,002 & 400,584 & 25 \\
\hline $24-30$ & 10,740 & 253,385 & 16 \\
\hline $31-50$ & 21,085 & 590,815 & 36 \\
\hline $51+$ & 15,659 & 345,945 & 21 \\
\hline Unknown & 4,171 & 39,647 & 2 \\
\hline Total & & $1,630,376$ & \\
\hline
\end{tabular}

wrote a series of AWK scripts to remove html tags so that only the spoken words remained. Additional AWK scripts were written to tag frequency counts for speaker status, which is clearly indicated within each transcription (for a summary of speaker attributes, see Table 1). The factorial combination of speaker attributes recorded with the speech in the MICASE results in a total of 128 possible speaker groups; however, as illustrated in Table 2, only 56 groups were represented. Not surprisingly, an analysis of the spoken frequency counts reveals that not all groups are equally represented. For example, $54 \%$ of all words spoken derived from female speakers, and $46 \%$ derived from male speakers. Thus, to facilitate meaningful comparisons across gender, age, college role, or language status, we also computed relative frequency (i.e., frequency of word/total number of words spoken by the speaker group).

\section{Frequency and Speaker Variability}

To our knowledge, our spoken frequency database is the first word frequency database tagged for speaker characteristics, which allows for a number of interesting analyses with implications for gender and developmental studies. Inspection of Table 3 reveals that although each speaker group is not equally represented in the original corpus, there are sufficient data for a number of between-groups comparisons. For example, females in the 17-23-year age group said LIKE 6,296 times compared to 2,680 occurrences for male speakers in the same age group, making females more than twice as likely as males to say LIKE. Although the same pattern emerges with relative frequency

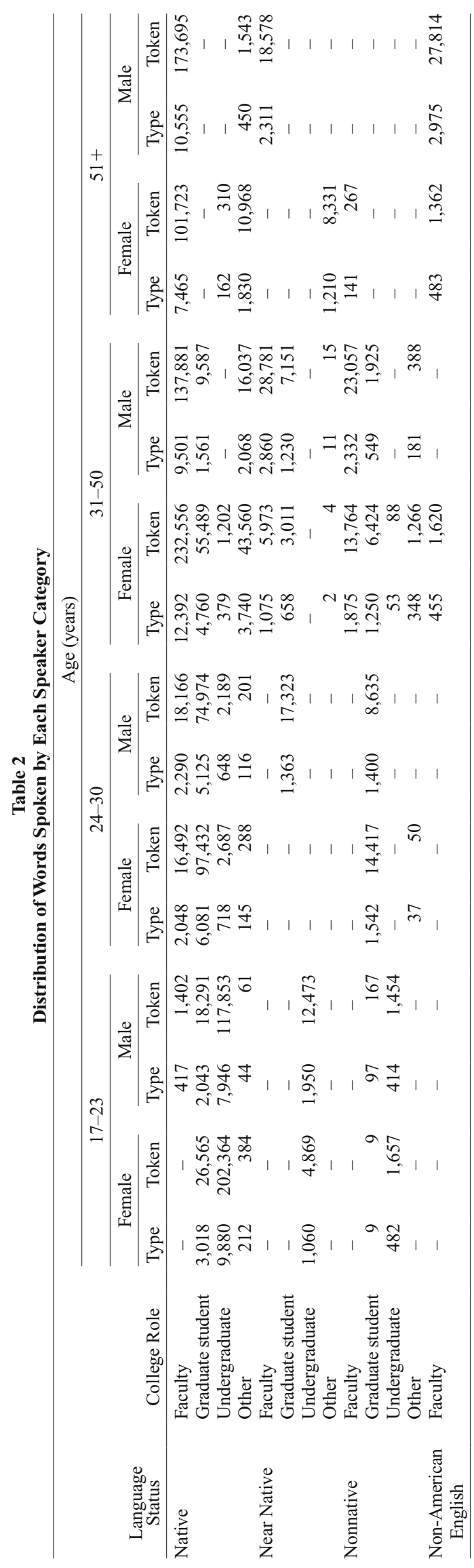


Table 3

Number and Percentages of Different Groups (Out of 56) With the Specified Minimum Type or Token Count

\begin{tabular}{rrrrrr}
\hline & \multicolumn{5}{c}{ Token } \\
Type Count & $n$ & $\%$ & Count & \multicolumn{1}{c}{$n$} & $\%$ \\
\hline $500+$ & 37 & 66 & $1,000+$ & 43 & 77 \\
$1,000+$ & 31 & 55 & $2,000+$ & 34 & 61 \\
$1,500+$ & 26 & 46 & $3,000+$ & 32 & 57 \\
$2,000+$ & 22 & 39 & $4,000+$ & 31 & 55 \\
$2,500+$ & 15 & 27 & $5,000+$ & 30 & 54 \\
$3,000+$ & 12 & 21 & $10,000+$ & 24 & 43 \\
$4,000+$ & 10 & 18 & $15,000+$ & 20 & 36 \\
$5,000+$ & 8 & 14 & $20,000+$ & 14 & 25 \\
$10,000+$ & 4 & 7 & $30,000+$ & 10 & 18 \\
& & & $40,000+$ & 10 & 18 \\
& & & $50,000+$ & 9 & 16 \\
& & & $75,000+$ & 7 & 12 \\
& & & $100,000+$ & 6 & 11 \\
& & & $150,000+$ & 3 & 5 \\
\hline
\end{tabular}

measure, the difference is less extreme (female $=2.58 \%$, male $=1.72 \%$ ). Not surprisingly, the frequency database reveals that LIKE usage declines with age. Other age effects are readily observable. A quick analysis across the age ranges represented in the database (17 to $51+$ years) reveals a steady decline in the use of the words I and NO, which may have implications for theories of aging.

The raw spoken frequency counts and the relative frequency measure can be accessed easily through an online Web interface that we have constructed (wordplay.geneseo .edu). The interface allows the user to specify speaker characteristics (either for comparison across groups, or to limit the results to a specific group) and basic search criteria that includes the option to enter a word (or a word list). The user can make comparisons within an attribute (e.g., gender), or can explore interactions across attributes (e.g., gender $\times$ age). Independent of gender and developmental applications, it is clear that this spoken frequency database is applicable to word recognition studies.

\section{Frequency Effects and Visual Word Recognition}

Typically, researchers manipulate or control written frequency in word recognition studies (e.g., Connine \& Mullennix, 1990). Our first interest was to confirm that the spoken frequency counts that we generated approximate written measures. Consistent with the significant correlation previously observed between written and spoken frequencies (Brown, 1984), we observed a moderately strong, positive correlation between log written frequency (Kučera $\&$ Francis, 1967) and log spoken frequency $[r(17,170)=$ $0.754, p<.01]$, and this relation suggests that a written measure can be replaced with spoken counts. Given the well-established (e.g., Brown \& Watson, 1987) negative correlation between familiarity and word recognition (assessed via lexical decision or naming) such that high frequency words are recognized faster than low frequency words, our second interest was to assess the predictive validity of our spoken frequency counts with respect to behavioral data. Given that our spoken frequency counts are distributed in a Zipfian manner (see Baayen, 2001), all analyses are based on log-transformed data.

Balota et al. (2002) collected lexical decision (LD) and naming latencies for over 40,000 visually-presented words, 17,170 of which occur in both our spoken frequency database and the Kučera and Francis (1967) database. As expected, LD latencies were predicted by both the written and spoken frequency $[r(17,170)=-.490$, $p<.01$ and $r(17,170)=-.404, p<.01$, respectively]. Likewise, naming latencies obtained from the Balota et al. (2002) database were predicted by both the written and spoken frequency measures $[r(17,170)=-.405, p<.01$ and $r(17,170)=-.334, p<.01$, respectively].

Although the observed correlations between the behavioral measures of visual word recognition and frequency were stronger for written counts relative to spoken counts, closer inspection of the data revealed that in some cases spoken frequency was a better predictor. Given that the LD and naming data (Balota et al., 2002) derives from a student population (across 6 different universities), we expected that spoken frequencies derived from the 17-23year-old age group would best reflect participant familiarity and therefore would be the best predictor of recognition (N.B., a comparable analysis is not possible with written frequency). To increase the sensitivity of our test, separate analyses were conducted for the top, middle, and bottom frequency ranges. Fisher's $z$ transformation was employed to compare the Pearson coefficients observed for spoken and written frequency counts as predictors of lexical decision and naming latencies. As illustrated in Tables 4 and 5,

Table 4

Pearson $r$ Correlation Coefficients Reported for Log-Transformed Data

\begin{tabular}{|c|c|c|c|c|c|c|}
\hline \multirow{2}{*}{$\begin{array}{c}\text { Frequency } \\
\text { Range }\end{array}$} & \multirow[b]{2}{*}{ Written } & \multicolumn{5}{|c|}{ Spoken (years) } \\
\hline & & All & $17-23$ & $24-30$ & $31-50$ & $51+$ \\
\hline \multicolumn{7}{|l|}{ Top Third } \\
\hline LD & -0.152 & -0.159 & -0.186 & -0.131 & -0.138 & -0.156 \\
\hline NAM & -0.193 & -0.206 & -0.251 & -0.168 & -0.179 & -0.201 \\
\hline \multicolumn{7}{|l|}{ Middle Third } \\
\hline LD & -0.147 & -0.096 & -0.182 & -0.032 (n.s.) & -0.033 (n.s.) & -0.047 (n.s.) \\
\hline NAM & -0.113 & -0.088 & -0.180 & -0.020 (n.s.) & -0.017 (n.s.) & -0.076 \\
\hline \multicolumn{7}{|l|}{ Bottom Third } \\
\hline LD & -0.201 & -0.071 & -0.152 & -0.019 (n.s.) & -0.034 (n.s.) & -0.014 (n.s.) \\
\hline NAM & -0.137 & -0.075 & -0.186 & -0.023 (n.s.) & -0.020 (n.s.) & $-0.045(p<.10)$ \\
\hline
\end{tabular}

Note-LD, lexical decision latency; NAM, naming latency (Balota et al., 2002). Unless otherwise noted, all correlations are significant at $p<.01$ (two-tailed). 
Table 5

Fisher $z$ Tests to Compare Observed Correlations Reported in Table 4

\begin{tabular}{|c|c|c|c|c|c|c|}
\hline \multirow{4}{*}{$\begin{array}{l}\text { Frequency } \\
\text { Range }\end{array}$} & \multicolumn{6}{|c|}{ Fisher $z$} \\
\hline & \multicolumn{4}{|c|}{ One-Tailed } & \multirow{2}{*}{\multicolumn{2}{|c|}{$\begin{array}{l}\text { Two-Tailed } \\
\text { Spoken (All) } \\
\text { vs. Written }\end{array}$}} \\
\hline & \multicolumn{2}{|c|}{$\begin{array}{c}\text { Spoken }(17-23 \text { years }) \\
\text { vs.Written }\end{array}$} & \multicolumn{2}{|c|}{$\begin{array}{l}\text { Spoken (17-23 years) } \\
\text { vs. Spoken (All) }\end{array}$} & & \\
\hline & Diff & $z$ & Diff & $z$ & Diff & $z$ \\
\hline \multicolumn{7}{|l|}{ Top Third } \\
\hline LD & -0.034 & -0.945 (n.s.) & -0.027 & -0.745 (n.s.) & -0.007 & -0.200 (n.s.) \\
\hline NAM & -0.058 & $-1.654^{*}$ & -0.045 & $-1.290^{\dagger}$ & -0.013 & -0.365 (n.s.) \\
\hline \multicolumn{7}{|l|}{ Middle Third } \\
\hline LD & -0.035 & -0.969 (n.s.) & -0.086 & -2.373 & 0.051 & 1.404 (n.s.) \\
\hline NAM & -0.067 & $-1.866^{*}$ & -0.092 & -2.542 & 0.025 & 0.676 (n.s.) \\
\hline \multicolumn{7}{|l|}{ Bottom Third } \\
\hline LD & 0.049 & $1.415^{\dagger}$ & -0.081 & $-2.286^{*}$ & 0.131 & 3.701 \\
\hline NAM & -0.049 & $-1.394^{\dagger}$ & -0.111 & -3.125 & 0.062 & $1.732^{\dagger}$ \\
\hline
\end{tabular}

Note-Negative differences (and negative $z$-scores) indicate a stronger negative correlation for the first count indicated (i.e., spoken [17-23 years], spoken [all]). Diff, the difference in correlation coefficients. Unless otherwise noted, all differences are significant at $p<.01 .{ }^{*} p<.05 . \quad{ }^{\dagger} p<.10$.

word recognition was always better predicted by spoken frequency counts specific to 17-23-year-old speakers relative to spoken frequency based on all speakers. In addition, spoken frequency based on 17-23-year-old speakers was in most cases a stronger predictor of naming latencies relative to written frequency.

To summarize, our spoken frequency counts are highly correlated with written counts (i.e., Kučera \& Francis, 1967), and spoken frequency is a significant predictor of visual word recognition as measured by lexical decision and naming tasks (Balota et al., 2002). Further, the strength of the correlation between spoken frequency and behavioral measures of word recognition appears to vary with speaker characteristics, and in some cases, spoken frequency accounts for significantly more variability in recognition latency relative to written counts.

\section{Conclusion}

Presumably, many people hear words more often than they read words, in which case, spoken frequency should provide a better measure of familiarity in comparison with written frequency. Consistent with this prediction, analyses confirmed that when the age of the speakers matched the age of participants that performed the naming task, spoken frequency, better predicted naming latencies relative to written frequency. Historically, the introduction of written frequency databases has prompted research questions and spurred investigations that would not have been possible without an objective measure of familiarity for a large number of words. Given the increasing sophistication of psycholinguistic investigations, the introduction of a large-scale spoken frequency database in American English has been long overdue. The spoken frequency counts reported in this paper are easily applied to traditional word recognition paradigms, and may also be used in research on cognitive processing as a function of age and/or gender.

\section{Availability}

The database reported in this article can be accessed at wordplay.geneseo.edu.

\section{AUTHOR NOTE}

Correspondence concerning this article should be addressed to M. J. Pastizzo, Psychology Department, SUNY Geneseo, One College Circle, Geneseo, NY 14454 (e-mail: pastizzo@geneseo.edu).

\section{REFERENCES}

Alegre, M., \& Gordon, P. (1999). Frequency effects and the representational status of regular inflections. Journal of Memory \& Language, 40, 41-61.

BAAYEN, H. R. (2001). Word frequency distributions. Dordrecht: Kluwer.

Balota, D. A., Cortese, M. J., Hutchison, K. A., Neely, J. H., Nelson, D., Simpson, G. B., \& Treiman, R. (2002). The English Lexicon Project: A Web-based repository of descriptive and behavioral measures for 40,481 English words and nonwords. Available at elexicon .wustl.edu.

BRown, G. D. A. (1984). A frequency count of 190,000 words in the London-Lund Corpus of English Conversation. Behavior Research Methods, Instruments, \& Computers, 16, 502-532.

Brown, G. D. [A.], \& Watson, F. L. (1987). First in, first out: Word learning age and spoken word frequency as predictors of word familiarity and word naming latency. Memory \& Cognition, 15, 208-216.

Connine, C. M., \& Mullennix, J. (1990). Word familiarity and frequency in visual and auditory word recognition. Journal of Experimental Psychology: Learning, Memory, \& Cognition, 16, 1084-1096.

Dewhurst, S. A., Hitch, G. J., \& Barry, C. (1998). Separate effects of word frequency and age of acquisition in recognition and recall. Journal of Experimental Psychology: Learning, Memory, \& Cognition, 24, 284-298.

FranCIS, W. N., \& Kučera, H. (1982). Frequency analysis of English usage. Boston, MA: Houghton Mifflin.

GERHAND, S., \& BARRY, C. (1998). Word frequency effects in oral reading are not merely age-of-acquisition effects in disguise. Journal of Experimental Psychology: Learning, Memory, \& Cognition, 24, 267-283.

KučERA, H., \& FranCIS, W. N. (1967). Computational analysis of presentday American English. Providence, RI: Brown University Press.

Simpson, R., Swales, J., \& BRIgGS, S. (2002). The Michigan corpus of academic spoken English. Retrieved July, 2005, from www.lsa.umich .edu/eli/micase/index.htm.

\section{NOTE}

1. To generate frequency counts that reflect spoken rather than written language, we deemed it appropriate to exclude words that were simply read aloud by the speaker.

(Manuscript received November 6, 2006; revision accepted for publication January 23, 2007.) 